\title{
O TRÁGICO: \\ EXPERIÊNCIA E CONCEITO
}

Ubaldo PUPPI*

RESUMO: O conceito do trágico está de algum modo ligado à violência. O presente estudo pretende estabelecer a relação essencial vigente entre violência institucional e situação trágica, a situação trágica sendo ao mesmo tempo conseqüência e denúncia da violência institucional. Assim entendido, o trágico é primeiramente expresso sob forma poética, na arte dramática denominada precisamente tragédia; em seguida, por derivação, sob forma conceitual, na análise da própria realidade histórica. A análise da história atual poderá revelar todo o potencial trágico acumulado na violência do poder.

UNITERMOS: Trágico; tragédia; violência do poder; violência sofrida; violência denunciada; denúncia poética; denúncia conceitual.

\section{INTRODUÇÃO DO TEMA E AO TEMA}

À primeira vista, o significado da tragédia é um desses conceitos que não oferecem dificuldade à compreensão. Vinculase ele obviamente com a manifestação da violência. A surpresa porém, e quase sempre a decepção, começa quando se procura conhecer a natureza dessa vinculação. Não é de per si a ação truculenta ou a truculência do actante que define a tragédia. Nem toda truculência é trágica, o que não quer dizer que alguma vez deixe de ser violenta. Antecipando, para posteriormente fundamentar a afirmação, seja dito em seco que a situação configurada pelo conceito do trágico tem sua causa e origem na estrutura do poder. Procurar determinar com precisão essa relação entre violência e estrutura de poder, é toda a pretensão deste artigo.

Não se trata, como se vê, de uma postura convencional. Precisamente por isso obriga a descartar previamente a ilusão provocada pela costumeira segurança com a qual o conceito do trágico é mani- pulado, mesmo quando apoiado em respeitáveis tradições interpretativas. Ao contrário daquelas participações taxinômicas que Aristóteles considerava como facilmente reconhecíveis, mas que designava como "inominadas", chega-se à constatação que estamos agora diante de um "nome" que encobre um significado ainda ignorado. E tanto maior é a errância, aqui, quanto mais se o supõe obviamente conhecido; ou, inversamente, tanto mais misterioso se revela quanto maior a preocupação em elucidá-lo.

Se por um lado são descartadas as interpretações tradicionais, por outro lado é preciso prevenir contra estereótipos ideológicos contemporâneos. Uma possível coincidência de expressão com eles, implica que se estará postulando aqui outra pauta de leitura que a deles, e a partir da qual poderão ser avaliados. A perspectiva dessa leitura, de alcance universal, não foi elaborada a partir de uma situação particular e de suas circunstâncias, mas tem por fundo de referência a própria história e alguns de seus avatares mais pertinentes. Está aí a razão pela qual proporciona o

\footnotetext{
* Professor Titular do Departamento de Filosofia - Faculdade de Educação, Filosofia, Ciências Sociais e da Documentação - UNESP - 17500 - Marilia - SP - Brasil.
} 
quadro categorial requerido para analisar e compreender a tragédia vivida pelo mundo atual: tragédia generalizada, consubstanciada na violência do poder da qual a violência da sociedade é outra face, e mal dissimulada pelos órgãos geradores da informação oficial.

O sentido real do trágico, por oposição ao seu sentido ficcional e poético, até hoje não mereceu estudos apropriados que o integrassem como categoria filosófica. A nível das concepções mais vulgarizadas, duas delas dividem as preferências. Segundo a primeira, o trágico seria uma tonalidade afetiva, própria da existência, no rastro de Unamuno: uma forma de sentimento heróico, previsível em uma vida ef etivamente assumida e independentemente do contexto histórico: "sentimento trágico da vida'. Na segunda concepção, o trágico seria uma sobredeterminação, no sentido que a psicanálise atribui a essa palavra, o que faria do trágico um mero epifenômeno da vida afetiva, conotado no lugar-comum "bom senso não faz tragédia.",

Se sob o prestígio dessas ou de outras influências, pouco importa o fato é que todo o mundo acredita possuir algum entendimento do trágico. Do contrário, não empregaria a palavra, nem sâberia de que se está falando quando a ouve pronunciada. É, aliás, a esse nível que se institui dialeticamente para cada um a problemática cujo aprofundamento, por sua vez, nega, supera e talvez recupera aquele entendimento primeiro e sempre provisório. É ponto pacífico que a intenção de aprofundamento pode permanecer aleatória e infundada, sem acessão a esse estágio metódico. Além disso, a estratégia metódica da dialética inventiva é de outra ordem que a estratégia do apriorismo científico. A primeira é própria de um processo críticohermenêutico em demanda de critérios teórico-interpretativos, ao passo que a segunda é característica do processo rigidamente teórico que opera por ruptura epistemológica e subsunção lógica.
Perfilhando a estratégia da dialética inventiva, foi formulada a seguinte hipótese heurística, isto é, uma hipótese inicial e provisória, por oposição aos axiomas do apriorismo teórico, que são antes um verdadeiro "anipotheton", epistemológico. Preserva ela tanto quanto possível a gênese e os dados da questão "o conceito do trágico nasceu, formou-se e desenvolveuse no contexto da ficção poética, de onde foi transferido para o plano da vida real. Contudo, em sua dimensão existencial, pessoal e histórica, - esse conceito permanece confuso e obscuro, incerto e polissêmico"'.

A hipótese, uma vez formulada, conduziu a pesquisa em direção às duas linhas complementares aí implicadas. A primeira consistiu em buscar no teatro, nas obras precisamente denominadas tragédias, o significado originário e paradigmático do termo pesquisado; isso, sem detença na estranha etimologia do termo, questão no caso irrelevante. A segunda linha de pesquisa obrigou a buscar na linguagem e nos filósofos a conceituação que dela se fez, não só ou principalmente como gênero teatral, mas a partir do gênero teatral.

Este artigo, seja dito a título de esclarecimento, não é a pesquisa in fieri, nem o fac-símile da pesquisa uma vez chegada a termo; tampouco pretende reproduzir pari passu as etapas que conduziram à definição procurada. Tanto mais que em toda pesquisa desse gênero faz-se presente, se daí não se origina a própria intenção da pesquisa, a imponderável participação de um questionamento inveterado e vivido que acaba por fixar-se como curiosidade obsessiva. O artigo será pois uma tematização econômica e a posteriori do resultado de todo um processo inventivo e metódico, respeitadas as linhas de clivagem da problemática instituída.

\section{DO TEATRO À VIDA}

A primeira linha de pesquisa, acima mencionada, levou à leitura programada 
de toda a produção teatral conhecida como trágica e considerada significativa para o tema: em gabinete de biblioteca o equivalente de um trabalho de campo. A constatação direta que daí resultou foi a de que a concepção do trágico investida na ação dramática possui três termos essenciais e definientes; cada um dos dois primeiros sendo constituídos de uma série de componentes, e o terceiro indicando a relação especial que se estabelece entre eles. A primeira série é a dos componentes existenciais, vividos pela personagem trágica sob a égide da fatalidade ou inevitabilidade: o mito do destino. A segunda, é a série dos componentes externos, que desencadeiam o processo do destino. O terceiro termo, a vítima do destino, literalmente o "destinatário", ou personagem trágica, na origem é sempre concebida como herói. Este último termo, aparentemente insignificante, adquire, em determinado estágio ideológico da história, capital importância para a caracterização do trágico.

Diante da força desencadeada pelos componentes externos, isto é, do "destino" ( $\mu$ õı $\alpha)$, o “destinatário" sofre inexoravelmente, em seus componentes existenciais, um ef eito correspondente de violência ( $\dot{\alpha} \nu \dot{\alpha} \gamma \chi \pi)$. O “destino-ativo",

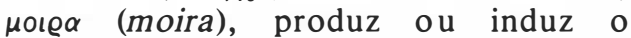

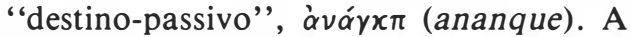
moira é concebida como uma instituição mítica que sela a sorte (ananque) de indivíduos escolhidos. A situação trágica é, portanto, uma situação de violência institucional sofrida individualmente no plano existencial.

Não é passivamente, porém, que o “destinatário"' da violência sofre e reage. Passivo tem dois significados: "ser o suporte da violência" e "reagir acomodadamente". O “destinatário" suporta a violência, mas luta agonicamente, isto é, como herói, contra sua causa próxima e emissária, mesmo sem saber que na escatologia trágica será sempre um herói vencido. Precisamente, a personagem trági- ca, na demiurgia do autor dramático, não é concebida para vencer, mas, pela fatalidade de sua derrota na qual são mostradas todas as últimas conseqüências a que leva a violência instituída, é proposta como denúncia.

Há duas óticas, portanto, na situação trágica, uma indissociável da outra: a ótica da personagem, que ignora a verdadeira causa ou causa remota da violência sofrida, e tudo o que consegue enxergar, o vê do ponto de vista do vencido; a ótica do autor, que denuncia ao público a violência institucional e causa do infortúnio que, por sua vez, causa o ponto de vista do vencido. Denúncia pelo sofrimento até as últimas conseqüências, eis o complemento definidor da situação trágica. $\mathrm{Na}$ íntegra: "situação de violência institucional, sofrida individualmente até as últimas conseqüências como denúncia".

Dessa definição derivam dois corolários. Primeiro: a causa do infortúnio vivido pela personagem trágica é desconhecida para ela, não para o autor; a inconsciência do Édipo Rei é um estratagema montado na consciência e por decisão de Sófocles. Segundo corolário: o autor trágico faz arte, não produz reforma nem promove revolução. Enquanto tal, não reforma nem revoluciona; denuncia. A tragédia é uma arte de denúncia. Denuncia o contexto opressor, a violência contextual, servindo-se da personagem trágica como instrumento de sua denúncia. O público, supostamente inconsciente como a personagem, é levado, por mediação da ideologia do vencido, ao nível de consciência do autor. Que portanto a tragédia intervenha positivamente na formação da consciência coletiva é tão irrecusável como irrecusável é o fato que só a consciência coletiva cria condições aceitáveis para as verdadeiras transformações sociais.

A definição acima é pertinente e abrangente. Contém os conceitos essenciais não redundantes e convém a todas as singularidades do definido. É portanto a 
chave que permite compreender, não só as diferenças entre as diversas concepções da tragédia, mas, sob as diferenças, também aquele fundo comum que as constitui a todas como legítimas tragédias. Por falta de bem compreender essas diferenças não se chega a bem definir o conceito do trágico, como inversamente, por falta de bem definir o conceito do trágico, não se chega a bem compreender essas diferenças.

É assim que ao nascer, na Grécia Antiga, a tragédia é de cunho essencialmente religioso, como todo o mundo sabe. Resta, porém, saber que ela é de natureza religiosa para poder caracterizar a violência da religião mítica num momento de emergência dos direitos da razão e da autoafirmação do homem. Cabe a René Girard $^{3}$ o mérito de ter demonstrado que a tragédia grega foi a primeira e grandiosa denúncia histórica da violência institucio$\mathrm{nal}^{5}$.

Com Shakespeare, sobretudo o da maturidade, a denúncia religiosa da tragédia grega é substituída pela denúncia da violência maquiavélica, institucional na política ou instituída por políticos sem escrúpulo. Pela primeira vez a tragédia veste roupas novas, confeccionadas agora no atelier da política, com o estofo da ambição e vontade de poder, da intriga e astúcia, de evicções e desterros ou homicídios. Já é a tragédia "política", no sentido de Machiavel, mas não ainda a tragédia "social" no sentido moderno.

Shakespeare porém, fiel nesse particular à norma clássica, ainda centraliza o desenrolar da tragédia em torno do herói pinçado na classe social dominante e "no auge da fama e da prosperidade"'1. Büchner, com Woyzeck, é quem derruba de seu trono o herói tradicional e, em seu lugar, exalta a humildade da personagem trágica, constituída de anti-heróis anônimos, chamando assim a atenção do espectador para a classe social dominada. Mas se Woyzeck, - proletário da primeira revolução industrial, anterior porém aos escri- tos e à ação de Marx, - já é a vítima trágica da injustiça social, esta não é todavia associada às relações de produção.

Mais recente metamorfose no gênero, a tragédia "social" está excelentemente representada entre nós com "A Gota d'Água', de Paulo Pontes e Chico Buarque de Holanda, que se inspira, como em plano afastado, na "Medéia" de Eurípedes e, como em primeiro plano, na “Medéia" de Eduvaldo Viana Filho. A variante contemporânea da tragédia denuncia, sempre por meio de pobres personagens marcadas como vítimas exemplares, a violência institucional contida nas contradições da formação econômica e política manipulada por centros esotéricos de decisão.

O estudo da tragédia em sua natureza e em sua história autoriza tirar as seguintes conclusões. 1. Existe uma característica existencial do fenômeno denominado trágico. 2. Os componentes existenciais do fenômeno trágico se revelam indissoluvelmente relacionados com componentes externos, que são de ordem contextual ou institucional, e pelos quais são desencadeados. 3. O conjunto dos componentes externos do fenômeno trágico variou no correr da história da tragédia, acompanhando grosso modo as variações da própria história das ideologias: de míticoreligiosa na origem, se estende e se substitui gradualmente pelo "político", numa primeira passagem, e pelo "social", numa segunda passagem. 4. Obviamente, certos componentes existenciais do fenômeno trágico também sofreram alterações, enquanto outros permaneceram inalterados. Inalterado permanece o "sofrer as conseqüências de modo exemplar', isto é, "até as últimas conseqüências, como denúncia' ; alteradas, em cada passagem, serão as relações existenciais (individuais e sociais) provocadas a partir de contextos, quer "mítico-religioso", quer "político", quer "social".

É chegado o momento para a explicação, já aflorada antes, sobre o componen- 
te que sempre permanece inalterado no fenômeno trágico, consignado na quarta conclusão acima: "sofrer (as consequências da violência institucional), de modo exemplar, até as últimas consequệncias, como denúncia". $\mathrm{Na}$ origem da tragédia, essa característica é associada à figura do herói. Por um processo a posteriori de sacralização, a vítima trágica é transformada em herói festejado. Aristóteles não o compreendeu, e a interpretação que dá 2 relacionando a majestade da tragédia com a exigência da alta linhagem da personagem trágica, para assim convertê-la em herói, é mera ideologia de classe dominante. Na verdade, a figura do herói é a imagem mítica, não só do trágico, mas também da denúncia da violência dos deuses. O herói, com ef eito, é vítima arbitrária, e uma vez aplacada a ira dos deuses, descarregada sobre ele, a normalidade retorna à comunidade, cumulada ademais de favores, mas sempre e ainda como bem mostrou R. Girard, graças à mesma vítima, agora considerada como vítima sacrificial. Ela não é ré, nem seu sofrimento expiação, mas uma como espécie metafísica de exutório, por onde são drenados - e portanto revelados - os malefícios da violência dos deuses. Daí o valor exemplar do herói como denúncia dessa violência e como símbolo em negativo de sua superação.

A função da catarse, característica da tragédia, situa-se precisamente aqui: proteger esse valor de exemplo, preservar a imagem da vítima, evitando assim que sua "diferença" seja reduzida a acontecimento rotineiro, como conviria à manutenção da violência institucional. $\mathrm{O}$ ef eito catártico sobre o público, com ef eito, leva-o a solidarizar-se com a vítima e, portanto, a assumir a mensagem que ela própria é. A catarse atua sobre o público "lavando-lhe a alma”, e simultaneamente "abrindo-lhe os olhos" para assim tirar a vítima da insignificância, da in-diferença; da rotina, enfim, que a convivência com a violência poderia acarretar. Sob esse enfoque, a concepção aristotélica da catarse é incompleta e detém-se em medíocre resultado: provocar a compaixão da vítima e o temor que o mesmo venha a ocorrer com cada um. Aristóteles viu bem o papel da compaixão, sob cujo impacto surge a solidariedade para com a vítima. Mas ao invés de vinculá-la à mensagem do "exemplo", reflui para um primário embora natural sentimento de defesa e segurança individual diante das ameaças do contexto violento, cuja injúria sofrida continuaria portanto inconsciente nos "destinatários" e incólume na sociedade onde campeia impune. O estagirita não se apercebeu da audácia contestatória dos trágicos gregos, contribuindo pelo contrário para esvaziá-la. Freud fez uma leitura aristotélica da tragédia grega, e a psicanálise ortodoxa se ressente até hoje dessa leitura.

Este novo enfoque da catarse autoriza substituir a figura do herói pelo da exemplaridade, que ela tem por função proteger e preservar. Não é pois pela importância de sua origem, como quer Aristóteles, que a vítima trágica se transforma em herói; é por sua exemplaridade que ela se destaca como denúncia. A figura do herói era tão-somente a crisálida mítica do realismo do exemplo. A identificação da "diferença" do exemplo por meio da alta posição da personagem, não só trai e põe a perder o verdadeiro alcance da catarse, mas deriva da mesma ideologia elitista que justificava o estatuto dos escravos, atribuindo-lhes, ontológica e politicamente, condição inferior. Se a crise moderna, não ainda o fim, da ideologia elitista põe termo à conotação da "diferença" do exemplo por meio do status da personagem, persiste ainda e sempre como essencial à tragédia a necessidade de diferenciação do valor exemplar pelo ef eito da ação catártica.

\section{UMA TAREFA DE FILÓSOFOS}

A segunda linha de pesquisa, acima anunciada, consiste em buscar nos filóso- 
fos o conceito existencial do trágico, isto é, o trágico como conceito do real; não mais, ou não apenas, como conceito poético. Um conceito, porém, sob pena de total indeterminação, nunca é solitário. Necessariamente ele é solidário: na ordem da inclusão, do sentido, da referência, da afirmação, da estrutura, do sistema. $\mathrm{Na}$ ordem da inclusão, de próximo em próximo se inscreve, pelo jogo das relações de semelhança e diferença, em classes sucessivamente mais amplas, até as últimas categorias genéricas. No extremo oposto a essas categorias genéricas últimas, a classe mais próxima é que confere as últimas determinações específicas. É pois, pela inclusão do conceito do trágico em sua classe mais próxima que ele receberá sua determinação mais precisa e sua definição essencial. Desde Sócrates, essa é uma tarefa de filósofos: neles devemos buscar o que procuramos.

Ler porém todos os filósof os indiscriminadamente, nem é factível para um mortal, mesmo que também filósofo, nem é bom critério. É preciso planejar metodicamente a leitura com base em um critério ao mesmo tempo racional, econômico e suficiente. O critério aqui assumido para orientar a leitura dos filósofos foi o seguinte. Há a priori uma tríplice posssibilidade de classificar o conceito real do trágico: ora como uma emoção específica entre outras, no sentido de tonalidade afetiva; ora como um "existencial" (eksistential) entre outros, na concepção que lhe dá Heidegger opondo "eksistential" a "ekistentiell", este situando-se na classe anterior; ora como uma situação limite entre outras, no sentido de Jaspers. Adotando essa tríplice possibilidade como três pistas para a leitura dos filósofos, a pesquisa chegou às seguintes conśtatações.
1. Em nenhum dos filósof os que classicamente propuseram classificações ou estruturas das tonalidades af etivas do ser humano (pouco importa se com o nome de paixões, emoções, ou ainda sentimentos), o trágico, assumido hipoteticamente como uma dessas tonalidades específicas, de modo algum comparece: Platão, Aristóteles, Tomás de Aquino, Descartes, Bergson.

2. Tampouco comparece como "existencial"' (eksistential) em filósof os que recorreram a esse conceito ou a conceitos filosóficos afins: nem em Heidegger, na "analítica existencial", nem em Sartre, Gabriel Marcel ou Merleau Ponty. Há exceção para Kierkergaard e Unamuno, mas para eles, precisamente, o conceito do trágico não é classificável, por situar-se nos limites entre a razão e a Fé. Não são ambos instrutivos à pesquisa porque, de um lado, extrapolam da filosofia, colocando questões de ordem teológica, e, de outro lado, extrapolam do próprio conceito do trágico, que não foi elaborado sob regime cultural de fé sobrenatural, mas de razão natural. Além do mais, a Revelação cristã, na qual se funda a teologia da fé, destrói as condições de existência do antigo trágico de cunho religioso*. Para não trair, pois, o significado originário do conceito do trágico, que tem sua história e sua evolução embutidas na história do teatro, ou para não lhe atribuir simplistamente um significado vale-tudo, que levaria à confusão das línguas, é preciso antes determinar-lhe o significado preciso e as variantes pelas quais passou, e que constituem hoje a sua tradição. Só a partir daí se tornaria inteligível todo outro emprego derivado da palavra. Apelar pela tradição nem sempre é apego ao passado, pode ser exigência histórica de racionalidade e clareza de pensamento.

* Em contraposição, o horizonte cristão é por excelência instância de denúncia da violência inibidora, repressora e violadora dos direitos do homem e, mais ainda, de toda reverente consideração de existências humanas. Essa instância, num sentido, já foi anexada à própria teologia, integrando, sem porém esgotá-la, a hoje denominada teologia da libertação. Em outro sentido, amplia e reforça as possibilidades da arte trágica de conteúdo sócio-político-econômico. 
3. Rigorosamente falando, o conceito existencial do trágico também jamais foi catalogado como situação-limite. Essa conclusão precisa ser explicada. Em sentido estrito, situação-limite é um conceito de classe, peculiar a Karl Jaspers, que não inclui o trágico. Em sentido amplo, porém, o trágico para Kierkergaard e Unamuno seria uma situação-limite, sem prejuízo no caso para a restrição feita acima a respeito de ambos sobre a hipótese do trágico como existencial (eksistential). A diferença entre a posição de um e de outros pode ser formulada assim: para Jaspers, a situação-limite é um conceito de classe, mas a classe não inclui o trágico; para Kierkergaard e Unamuno, o trágico seria uma situação-limite, mas a situaçãolimite não é uma classe.

4.Os filósof os que trataram do trágico, o trataram predominantemente como conceito poético, isto é, com referência à tragédia enquanto gênero teatral. Quando o trataram metaforicamente, a partir do teatro, como conceito existencial ou como situação-limite, extrapolaram do suporte: este perde, ou não adquire, - seu significado preciso, enquanto a metáfora se torna tão imprecisa como o suporte. Entre os primeiros, os que o trataram predominantemente como conceito poético, estão: Aristóteles, Hegel, Nietzsche, Lukács. Entre os segundos: os já mencionados Kierkergaard e Unamuno. Lugar a parte ocupam autores que cruzam regiões de fronteira com a filosofia: Freud, R. Girard, Domenach.

Do ponto de vista ao qual chegou a pesquisa, tornou-se possível afirmar que a classe à qual pertence o conceito do trágico, tal como foi elaborado por ocasião da leitura da poesia trágica, é a classe da situação-limite. Mas se, por um lado, é preciso alargar o conceito de situaçãolimite de Jaspers, por outro lado é preciso restringir o conceito do trágico de Kierkergaard e Unamuno. Tal como é proposto nesta pesquisa, o trágico não é uma situação-limite nos termos estritos de Jas- pers, nem coincide com as propostas tanto do pensador dinamarquês, cọmo do espanhol. Com ef eito, a situação-limite jasperiana é puramente metafísica, abstrai da história, quando na verdade não é na realidade ontológica que se encontra o trágico e sim na história. Ali, tem ele apenas as condições permissivas de sua possibilidade, inscritas na finitude do ser do homem; aqui, as condições concretas de sua ef etuação, e a sua própria ef etuação.

As duas outras propostas localizam o trágico na confluência da razão natural com a fé do cristão, reduzindo ou conduzindo finalmente o trágico a um fenômeno de forte conteúdo teológico. A isso, entretanto, é preciso objetar, embora ao preço de alguma redundância, que: primeiro, o trágico não foi elaborado em função de situações teológicas no sentido pós-cristão do termo; segundo, o lúmen teológico, a fé do cristão, de acordo com sua natureza e com toda sua melhor tradição de vida e de doutrina, não violenta a natureza e a razão do homem, mas pelo contrário a eleva na escala do ser e do operar, e não pode por conseguinte constituir em si e por si condição suficiente para uma situação trágica; terceiro, o indivíduo, no que lhe concerne em próprio, sempre pode dramatizar, "fazer tragédia" a respeito de tudo e de nada, mas isso a nível das sobredeterminações e das idiossincrasias. A análise crítica dos filosofemas e da biografia dos dois autores não descarta a hipótese de contaminação de suas buscas e contradições íntimas por intrometimentos dessa ordem. De qualquer modo, contudo, é preciso reconhecer que um certo modo de tradução (traição) ideológica do discurso cristão, como aliás de todo sistema de valores, pode ser ocasião de situações trágicas, isto é, de mitos e relações sociais decorrentes que violentam a natureza, a razão e a liberdade. Mas não é esse o contexto visualizado pelos mencionados autores, o que não garante não tenham sido condicionados por ele. Se, na ótica da praxis social, esse desvio é 
um ópio para o povo, na ótica do logos e do ethos, pode ser trágico para o indivíduo.

Assim reformulada, a situação-limite é a classe à qual convém o trágico, já antes caracterizado como "um sofrimento exemplar até as últimas conseqüências". Por trágico, enquanto afetando pessoas e situações reais, entendo pois uma situação-limite especificada como um sofrimento exemplar provocado pela violência institucional.

Uma vez circunscrito o tema e proposta a definição do trágico, resta analisar em detalhe as duas partes constitutivas da definição. Toda definição propriamente dita é produzida mediante a determinação do gênero próximo e da diferença específica. A primeira parte da definição proposta, "situação-limite", constitui o gênero próximo; a segunda parte, "sofrimento exemplar provocado por violência institucional", constitui a diferença específica. O que, porém, é gênero próximo para a definição do trágico, já é determinação do gênero ulterior e mais geral "situação". Antes pois de saber o que é "situação-limite", é necessário reportarse à "situação". A análise fenomenológica faz ver que é na situação que se processa a interação, o ef eito sinérgico, entre de um lado reações pessoais e de outro lado o mundo físico e as formas institucionais (econômicas, sociais, políticas, culturais, religiosas; enfim, históricas).

Elucidado o conceito geral de situação, deve esta ainda ser determinada em sua modalidade de situação-limite. Com adições que ampliam a concepção olimpicamente metafísica de Jaspers, refundindo-a e m função do histórico, a concepção aqui adotada é mutatis mutandis a.dele, bem representada nesta passagem tirada da Einführung in die Philosophie: "Eu posso trabalhar para mudar uma situação. Mas há aquelas que subsistem em sua essência, mesmo que sua aparência momentaneamente se mo- difique e que sua onipotência se dissimule sob um véu: devo morrer, devo.sofrer, devo lutar, estou submetido ao acaso, encontro-me inevitavelmente preso aos laços da culpabilidade. Essas situações fundamentais implicadas em nossa vida, nós a chamamos situações-limites. Isso quer dizer que não podemos ultrapassá-las, não podemos transformá-las'.

Basta ai inserir o fator histórico, com as devidas implicações. Digamos então que as situações-limites nos são impostas, ou pela realidade ontológica, como quer ele, ou pela história, como também queremos nós; as primeiras aparecendo mesmo, em última análise, como condição da possibilidade aleatória das segundas. Quanto às implicações do fator histórico, devem elas ser aclaradas a partir das diferenças específicas. A diferença específica da situação-limite trágica é um "sofrimento" que, possuindo um caráter obviamente pessoal, se revela no entanto "exemplar'" para a comunidade, à qual é manifestado. E é manifestado à comunidade para a tomada de consciência do potencial de violência freqüentemente disfarçado nas pregas das relações sociais e da estrutura e manipulação do poder. Mas, além de postular um “sofrimento exemplar", o fenômeno trágico não predetermina mais nada. Não diz como será esse sofrimento e quais tonalidades afetivas serão acionadas. Afirma apenas que o sofrimento, para ser verdadeiramente exemplar, deve atingir "suas últimas conseqüências", o que quer dizer: os limites previsíveis da iniqüidade e atrocidade embutidas nas formações históricas.

O trágico, portanto, é o sinal natural de uma grave anomalia no corpo social. Assim como o sofrimento e o mal-estar físicos são o sinal algésico de alerta para o desvelamento da disfunção que ameaça a saúde e a integridade física, assim também o trágico, na ordem da experiência vivida, é a denúncia tácita das formas históricas violentas; denúncia com vistas a uma tomada de consciência coletiva. Eis 
por que, originando-se como experiência vivida, depende ainda de sua tematização para ser manifestado e comunicado. A tematização do trágico assume duas formas rentes, que são duas formas explicitas de denúncia da violência institucional: a forma da arte, particularmente o teatro, onde ocupa um espaço privilegiado sob o nome precisamente de tragédia; e a forma da análise conceitual. Na tragédia, a denúncia se identifica com o próprio teatro, formando um complexo semiótico no qual o discurso poético, de forma dialógica, se associa à ação mimética, ao passo que a análise conceitual se traduz em denúncia direta e explícita. A serviço desta se põe todo discurso crítico comprometido com a libertação do homem, pouco importa se proveniente da praxis política, do ensaio, do jornalismo, da ciência, da filosofia ou da teologia.

\section{EXPERIÊNCIA DO TRÁGICO E FOR- MAS DE EXPRESSÃO}

A pesquisa, que começou pela preocupação com as dimensões do conceito do trágico, de aparência a princípio complexa e obscura, chega finalmente a conclusões no fundo simples e claras. Sobre os pressupostos da fundamentação sucintamente indicada acima, torna-se legítimo afirmar que só existe uma experiência real do trágico, com ou sem sua conseqüente tematização, sob uma ou outra de suas formas gerais de expressão: a arte e o conceito. Mas seria igualmente legítimo resumir dizendo que, sob qualquer das formas de expressão, o que se comunica é a experiência trágica, e que a experiência provocada pela comunicação é sempre a mesma? Não é bem assim. A verdade aqui é outra e de cerio modo paradoxal, uma vez que o que a análise conceitual comunica não é a experiência do trágico, e que aquilo que o teatro provoca é uma experiência do trágico de outra ordem que a sua experiência real.

Com efeito, a análise conceitual do trágico não se destina a transmitir a experiência que tematiza, mas a fazer entender a situação trágica: daí seu caráter de denúncia direta e fundada. Inversamente, a tematização pela arte se destina a produzir nova experiência. Pois, se a tragédia é a tematização poética de uma experiência real, ela por sua vez desperta no expectador uma experiência poética.

Há por conseguinte, além da experiência real do trágico, uma sua experiência poética. Esta experiência apenas reproduz em emoções o que o paciente sofre de verdade como experiência real. A função dessa experiência catártica não é a de eludir a crueldade de uma situação histórica real, substituindo-a pela escapatória de um estetismo inoperante e tranqüilizador; pelo contrário, como foi visto mais acima, por sua própria natureza estética a catarse visa proteger e preservar a figura do exemplo proposto como denúncia da violência institutional. Mais do que de costume, aqui o estetismo é o maior inimigo da experiência poética. A experiência poética, na medida em que é verdadeira, sabe os riscos que corre. Para o estetismo, não há essa consciência, ele já sucumbiu.

Os riscos da experiência poética não são porém motivo para temê-la, pois afinal de contas a poesia é tão arriscada e indeclinável como a própria vida. Não é a poesia, mas a falta de poesia, que violenta, oprime, reprime, tortura, mata, desmata, polui, esteriliza. O tecnoburocrata faz sem poesia. O estetismo deixa fazer. A poesia trágica denuncia e compromete, com a denúncia, seu portador. 
PUPPI, U. - The Tragic: experience and concept. Trans/Form/Ação, São Paulo, 4: - 1981.

ABSTRACT: The concept of the tragic is somehow connected with violence. The present enquiry has the purpose of establishing the essential relationship existing between institutional violence and the tragic situation, the latter being at the same time consequence and denouncement of the former. Understood that way, the tragic is first expressed under a poetical form which is precisely called tragedy in dramatic arts: then under a conceptual form, in the analysis of the historical reality itself, by derivation. The analysis of current history may reveal all the potentiality of the tragic accumulated on the violence of power.

KEY-WORDS:Tragic; tragedy; violence of power; endured violence; denounced violence; poetical denouncement; conceptual denouncement.

\section{REFERÊNCIAS BIBLIOGRÁFICAS}

1. ARISTÓteles. - Poética, 1453 a 10.

2. ARISTÓtEleS. - Poética, 1453 a 7-22.

3. GIRARD, R. - La violence et le sacre. Paris, Grasset, 1972.
4. PLATÃO. - República VII, 510b - 511c

5. PUPPI, U. - Uma teoria da cultura: comentário crítico. Trans/Form/Ação, São Paulo, 1:241-65, 1974. 